\title{
Comparison of the Influence of Cooling Medium on Stress State during Superficial Hardening for the Hot-Work Tool Steel
}

\author{
A. Bokota, A. Kulawik and J. WróBel* \\ Częstochowa University of Technology, al. Armii Krajowej 19, 42-201 Częstochowa, Poland \\ Doi: 10.12693/APhysPolA.138.174 \\ *e-mail: joanna.wrobel@icis.pcz.pl
}

\begin{abstract}
The paper presents a complex analysis of superficial hardening for hot-work tool steel to optimize the residual stress state. It was assumed that the main factor influencing the quality of the hardened element is the use of an appropriate cooling medium. Two groups of cooling media were considered gases and solids. The group of gases is represented by air and solids by fluidised bed. The numerical algorithm of thermal phenomena is based on the finite element method solution of the non-stationary heat transfer equation. The model of estimating phase fractions and their kinetics is based on continuous heating and cooling diagrams. The stresses and strains were determined from the solution of thermoelasto-plasticity problem in the rate form. The numerical analyses of phase composition and hardening stresses in surface hardened elements made of hot-work tool steel were performed.
\end{abstract}

topics: hot-work tool steels, hardening, air cooling, fluidized bed, finite element analysis

\section{Introduction}

The research papers in the field of steel hardening can be divided into those that complex described the heat treatment process and those that focus on one phenomenon. The mathematical model of the described process should consist of at least three coupled parts: thermal, structural, and mechanical [1-3]. In order to ensure the reliability of results of numerical simulations of such a hardening process, especially due to significant changes in stress, apart from thermal, structural, and plastic strains also the transformation strains should be taken into account $[1,4]$. The proper selection of heating and cooling conditions is a factor that has a significant impact on the obtained results of numerical simulation of hardening. This is particularly important in modeling the hardening of hot-work tool steels that are easily hardened [5-7].

\section{Mathematical model of hardening}

The temperature fields are determined from solution of the heat transfer equation. This equation was supplemented by the appropriate initial and boundary conditions. The Neumann condition (heat flux modeling thermal isolation) was applied on part of the edge. On the rest of the edge the heat flux is determined by the difference between the boundary temperature and the surrounding medium. This condition is used for modeling the heating and cooling process $[6,8]$.

To determine during heating the temporary phase composition a continuous heating transformation

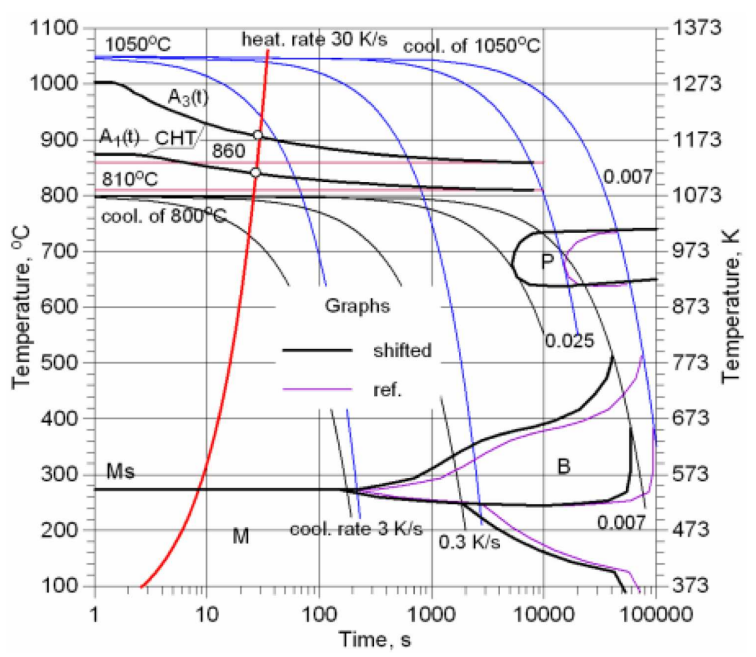

Fig. 1. The continuous cooling transformation and shifted diagrams for W360 steel.

diagram (CHT) was used. However, phase fractions and kinetics of cooling phase transformations are determined after analysis of the continuous cooling transformation diagram (CCT) for W360 steel (Fig. 1) [5, 6]. The austenite, pearlite or bainite fractions formed during heating or cooling are determined by the Johnson-Mehl-Avrami equations, whereas martensite content in the cooling process — by modified Koistinen-Marburger equation [1, 9].

Due to the different austenitization temperature analyzed in the example than the austenitization temperature for which the CCT chart was created, the literature diagram was correctly shifted $[2,6]$. 


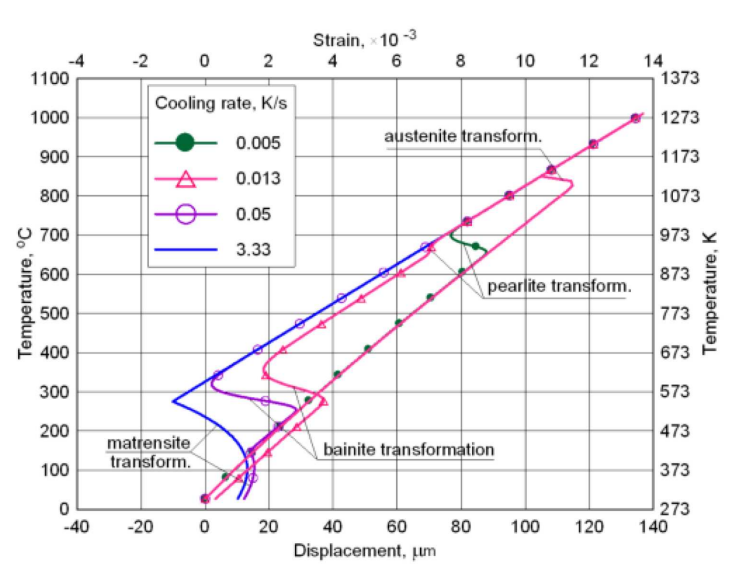

Fig. 2. Simulated dilatometry curves for established cooling rate (Fig. 1). The displacements are related to a base length of $10 \mathrm{~mm}$.

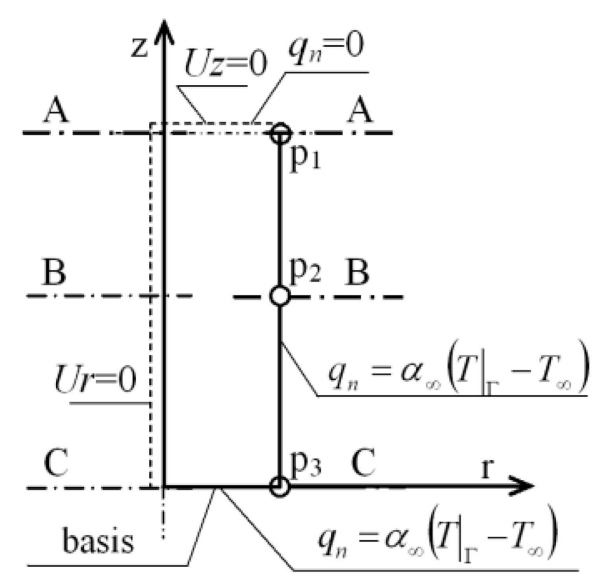

Fig. 3. The scheme of the system and assumed boundary conditions.

The thermal expansion coefficients of phase transformations were estimated on the basis of literature [2, 3, 5, 7]. The examples of the results of the simulations comparisons for established cooling rate (the average cooling rate in the range of $800-500^{\circ} \mathrm{C}$ (Fig. 1)) are presented in Fig. 2. The isotropic structural strains are calculated on the base of analysis of numerical dilatometric tests obtained for different cooling rate. The values of structural strain coefficient were equal to 2.0, 5.61, 5.92 and $1.9\left(\times 10^{-3}\right)$ for austenite, bainite, martensite, and pearlite, respectively.

Analyzing the results of the simulation of the transformation kinetics, it is noted that the martensite structure is already achieved from a cooling rate of $3 \mathrm{~K} / \mathrm{s}$ (Figs. 1, 2). In order to obtain a bainitemartensite structure the cooling must be carried out with a cooling rate less than $3 \mathrm{~K} / \mathrm{s}$, e.g. air cooling.

The equilibrium equation and constitutive relations are used in the rate form $[1,6]$. The equilibrium equation is completed by initial conditions and boundary conditions which provide external statically determinate (Fig. 3). The Huber-Misses plasticity condition was used to determine plastic strains (isotropic hardening), while the Leblond model was used to determine transformations plasticity [4].

\section{Examples of numerical calculations}

To hardening simulation the axisymmetric element with dimensions $\varphi 50 \times 100 \mathrm{~mm}$ was used (Fig. 3).

In the calculations it was assumed that the initial temperature of the steel element was $300 \mathrm{~K}$, and the initial structure was pearlite. The considered element was heated in a fluidized bed with temperature $1550 \mathrm{~K}$. On the edges of the element the heat transfer coefficient of the fluidized bed was assumed equal to $2000 \mathrm{~W} /\left(\mathrm{m}^{2} \mathrm{~K}\right)$, whereas on the front surface the value of coefficient was reduced to $1350 \mathrm{~W} /\left(\mathrm{m}^{2} \mathrm{~K}\right)$ (this is $67.5 \%$ of the value - of the edges of the element) [10]. Heating was continued until the maximum temperature of $1380 \mathrm{~K}$ around point 3 (Fig. 3) was obtained. The temperatures $\mathrm{Ac}_{1}$ and $\mathrm{Ac}_{3}$ were equal to 1033 and $1133 \mathrm{~K}$, appropriately [5], but heating was continued to a higher temperature than the $\mathrm{Ac}_{3}$ temperature because the CHT diagram was used in the simulation. The obtained temperature distributions after finish of heating were presented in Fig. 4.

The cooling simulations were carried out for two different coolants: air (case a) and a fluidized bed (case b). In the case of air cooling, the heat transfer coefficient was approximated by a polynomial function with the use of mean square approximation based on the results presented in the papers $[2,7]$. The heat transfer coefficient of the fluidized bed was assumed equal to $350 \mathrm{~W} /\left(\mathrm{m}^{2} \mathrm{~K}\right)$ and $67.5 \%$ of this value on the front of the element. Cooling medium temperature was constant - $300 \mathrm{~K}$.

Hardened zones in the cross-sections of the element were presented in Fig. 5.
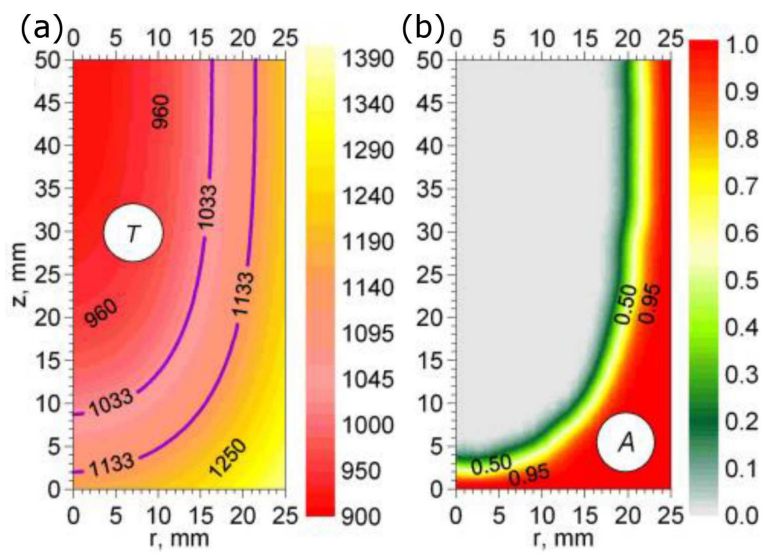

Fig. 4. The distributions of temperature (a) and austenite (b) after heating. 

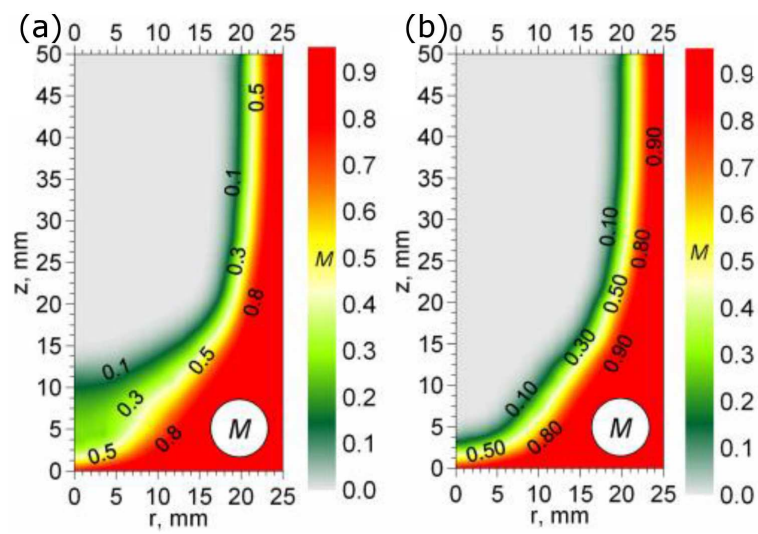

Fig. 5. The distributions of martensite: (a) cooling in air, (b) cooling in fluidized bed.
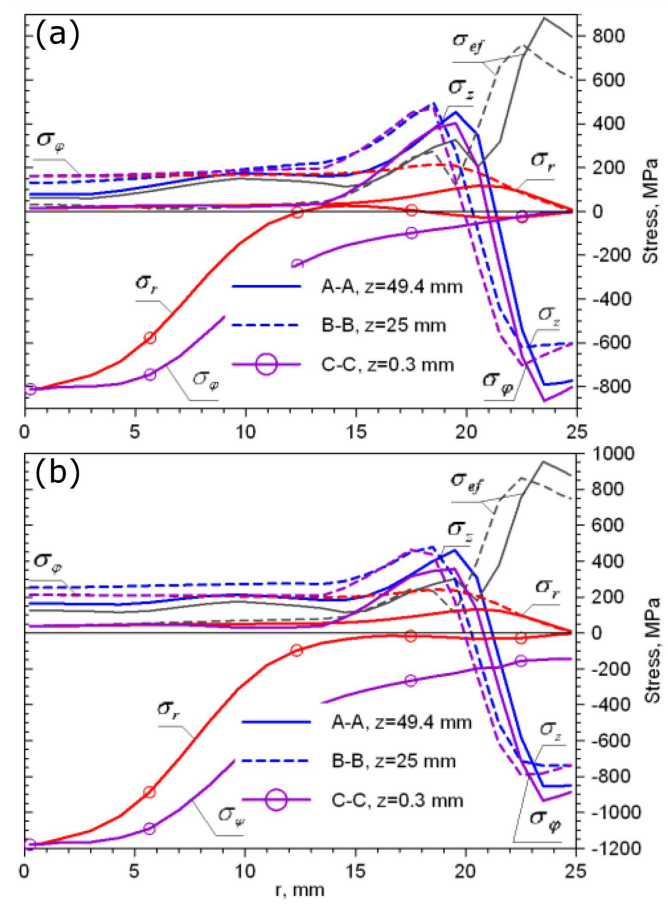

Fig. 6. The distributions of residual stresses along the radius in three cross-sections: (a) cooling in air, (b) cooling in fluidized bed.

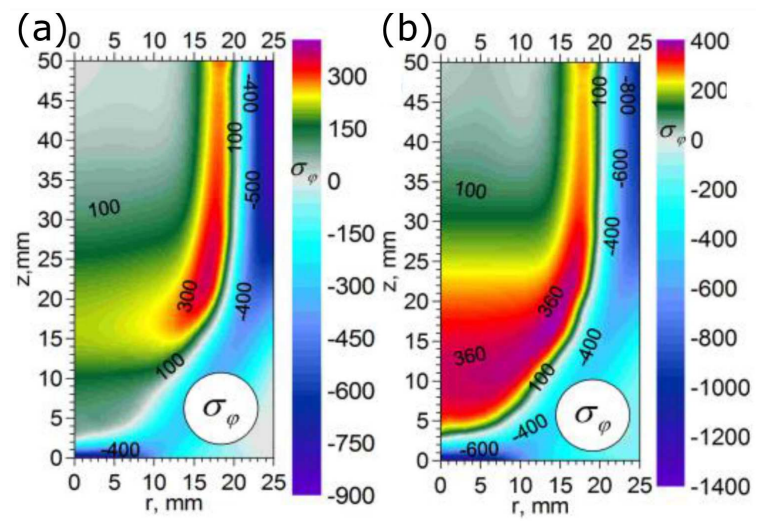

Fig. 7. The distributions of effective peripheral stresses: (a) cooling in air, (b) cooling in fluidized bed.
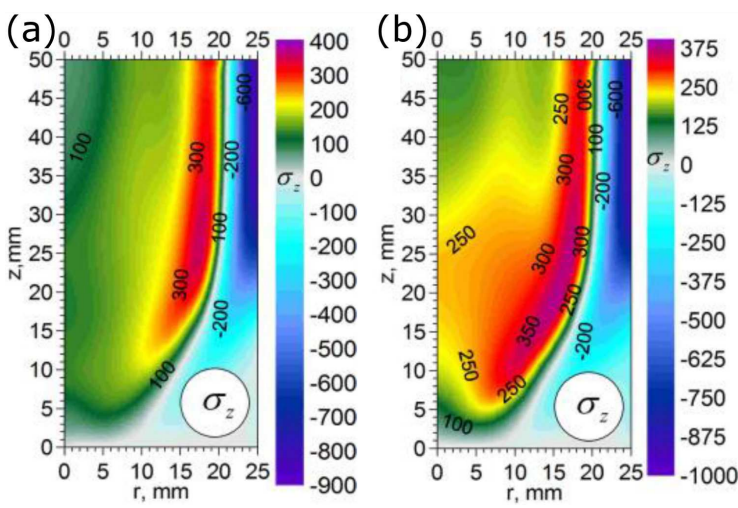

Fig. 8. The distributions of effective axial stresses: (a) cooling in air, (b) cooling in fluidized bed.

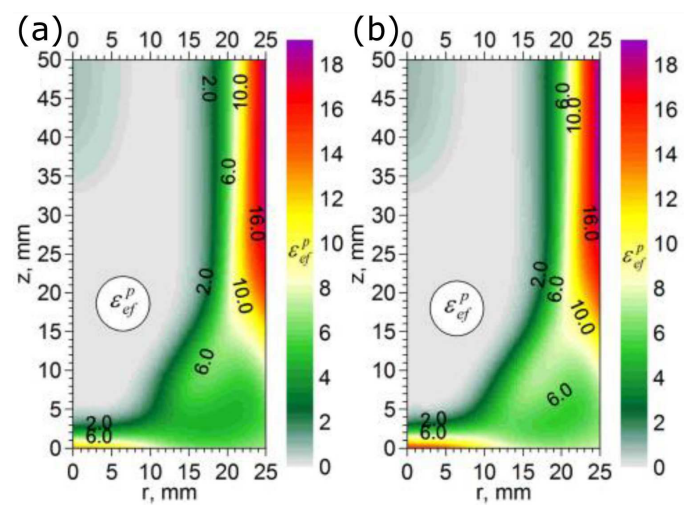

Fig. 9. The distributions of the effective plastic strains $\left(\times 10^{-3}\right)$ : (a) cooling in air, (b) cooling in fluidized bed.
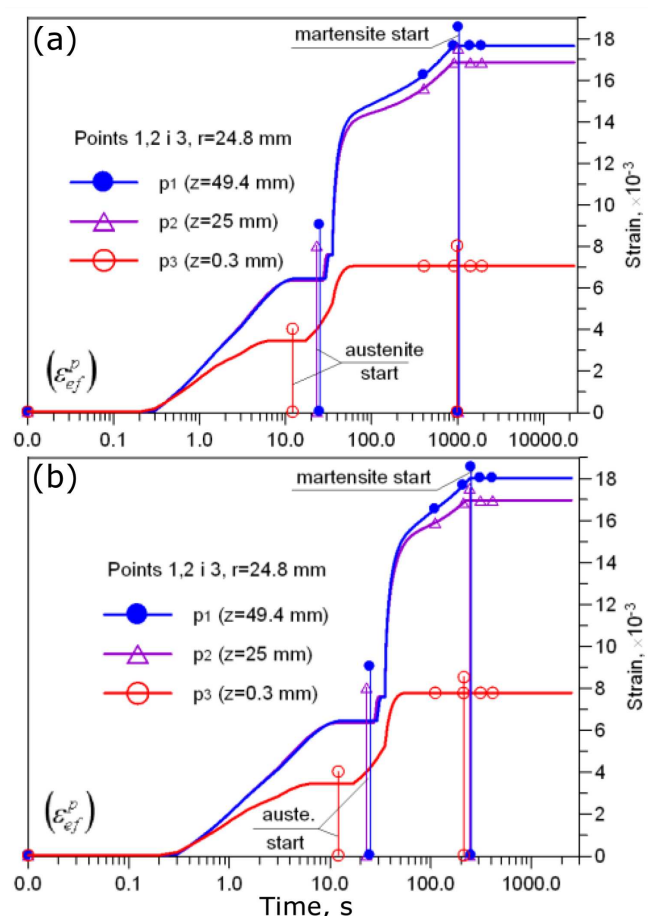

Fig. 10. History of the generation of effective plastic strains in the surroundings of the boundary points: : (a) cooling in air, (b) cooling in fluidized bed. 
In the simulation of mechanical phenomena, the Young modulus and the tangential modulus were dependent on temperature, while the yield point on the temperature and phase composition [3, 5]. These values were approximated by quadratic spline functions [6].

Distributions of residual stresses in the cross and in longitudinal sections after the cooling process, as well as plastic deformations and the history of the generation of plastic deformations, in point 2 of section B-B were shown in Figs. 6-10.

The components of the stress tensor (Fig. 3): $\sigma_{r}$ — radial, $\sigma_{\varphi}$ — peripheral and $\sigma_{z}$ — axial stresses.

\section{Conclusions}

In the first case (air cooling), in addition to the martensite and residual austenite, bainite $(\approx 5 \%)$ was also formed and consequently resulted in a lower proportion of martensite. The relatively slow cooling (in air) causes that the start of martensite is almost simultaneous at the edge points of the element, which cannot be ensured in conditions of more intense cooling. The start of martensite transformation is, in this case, varied (much earlier in the corner). Although these differences are small, it may be unfavorable to the stress generated in the cooling process. In the second case, due to the higher cooling rate, only martensite and residual austenite are of the final structures.

The obtained stress distributions were favourable. Normal stresses were compressive in surface layers (Figs. 6-8). In both cooling versions, the plastic flow ends before the start of the martensite (Fig. 10). The highest level of plastic strains occurred in the surface layers (Fig. 9) because the stresses were the highest there (Figs. 6-8).

\section{References}

[1] S.-H. Kang, Y.T. Im, J. Mater. Process. Technol. 183, 241 (2007).

[2] A. Kulawik, A. Bokota, Arch. Metall. Mater. 56, 345 (2011).

[3] M. Coret, A. Combescure, Int. J. Mech. Sci. 44, 1947 (2002).

[4] L. Taleb, F. Sidoroff, Int. J. Plast. 19, 1821 (2003).

[5] Warmarbeitsstahl Hot Work Tool Steel, BOHLER W360, Iso Bloc.

[6] A. Bokota, A. Kulawik, R. Szymczyk, J. Wróbel, Arch. Metall. Mater. 60, 2757 (2015).

[7] M.L. Fares, M. Athmani, Y. Khelfaoui, A. Khettache, IOP Conf. Ser. Mater. Sci. Eng. 28, 012042 (2012).

[8] M. Dowden, The Mathematics of Thermal Modeling, Taylor \& Francis, USA 2001.

[9] D.P. Koistinen, R.E. Marburger, Acta Metall. 7, 59 (1959).

[10] J. Jasiński, Oddziaływanie Złoża Fluidalnego na Procesy Nasycania Dyfuzyjnego Warstwy Wierzchniej Stali, Wydawnictwo Politechniki Częstochowskiej, Częstochowa 2003 (in Polish). 